\title{
Inventory Policies for Price-Sensitive Stock-Dependent Demand and Quantity Discounts
}

\author{
Nita H. Shah ${ }^{1 *}$, Monika K. Naik ${ }^{2}$ \\ Department of Mathematics, Gujarat University \\ Ahmedabad-380009, Gujarat, India \\ Email: ${ }^{1}$ nitahshah@gmail.com, ${ }^{2}$ monikaknaik@gmail.com \\ *Corresponding author
}

(Received June 16, 2017; Accepted August 4, 2017)

\begin{abstract}
It was usually observed in typical EOQ inventory models that the holding cost, the purchasing cost and the demand rate are constant and the purchasing cost is irrespective of the order size. But practically, the demand rate is based on various factors including sale price, seasonality and availability. Due to the lengthening of shortage periods, the holding cost per unit item increases. Also with the inclusion of quantity discounts, the unit purchasing cost is usually decreased for higher order sizes. This article addresses jointly with the inconsistency of the rate of demand, unit purchasing cost and unit holding cost for deteriorating items. This paper proposes a model based on an inventory problem including selling price of products and stock-dependent market demand rate, holding cost based on storage time and purchasing cost is influenced by order size by offering all units quantity discounts. An algorithm for estimating the optimum solution of decision variables by maximizing total profit and minimizing the overall cost of the model is developed in this paper. Validation of the developed model is confirmed with the help of a numerical example along with the sensitivity-analysis of decision variables by varying various inventory parameters.
\end{abstract}

Keywords - Deteriorating items, Quantity discounts, Price-sensitive stock-dependent demand rate, Storage-time dependent holding cost, Order- size dependent purchasing cost.

\section{Introduction}

Most of the earlier literature work based on inventory control models is derived with an assumption of fixed demand rate. In the majority of these models, demand rate is considered to be an independent exogenous variable. As such, demand rate is a very crucial factor in uplifting the total profit of any business. But practically, there are many factors like selling price, obtainability of items influencing demand rate. The decrease in selling price increases sales of many products. In real-world situations, the unit holding cost varies with storage duration due to the period of storeroom lease contract. Assuming the unit holding cost as a function of the time- spent in stock with a cost of holding as variable, grows either continuously or in a discrete way. This paper mainly focuses on developing an inventory model which includes the concept of deterioration of items kept in stock with continuously decreasing demand depending on selling price as well as inventory level at time $t$, with holding cost based on constant co-efficient as well as variable co-efficient, raises the cost linearly with respect to time period and the purchasing cost is influenced by order size. On the basis of these assumptions, and by framing a mathematical model, the optimal solution is computed by maximizing the total profit and minimizing the total cost.

Focusing on practical situations, and set of assumptions, rarely considered in the earlier literature, but has a much significant role in many industries like typically opted in food industries. Many of the processed food items require more sophisticated warehousing facilities, due to lengthier storage durations, and therefore time increasing holding cost is utilized. Furthermore, demand for food 
International Journal of Mathematical, Engineering and Management Sciences

Vol. 3, No. 3, 245-257, 2018

https://dx.doi.org/10.33889/IJMEMS.2018.3.3-017

items are price and time dependent as such these items are not unique, so customers can switch over to another food item choice or can move to another brand, once they face any rise in price, and also inventory level of food items are dependent on time as once deterioration of items begins inventory level decreases.

The market demand rate is assumed to fluctuate as a function, based on stock level, the price value or together, in models on inventory with rates of demand as variable one. An EOQ inventory model where the net profits are maximized on fulfilling the constraints like; budget and capacity of storage was developed by Sana and Chaudhari (2004), with the rate of demand jointly based on item obtainability and expenditures on advertisements. For deteriorating items with partial back-logging and demand rate based on a stock level with a bound on the extreme inventory level, an inventory model was derived by Min and Zhou (2009). Another inventory model with demand rate based on deteriorating stock level was proposed by Yang et al. (2010), permitting back-logging partially and including the inflation effect. An EOQ model with partial back-logging, with stock-dependent demand with manageable deterioration rate which develops the preservation strategies and estimates optimum order size to boost the total profit to maximum, was formulated by Lee and Dye (2012). Anand and Bansal (2016) investigated a predictive model to identify customer's satisfaction (dissatisfaction) with the firm's offerings using logistic regression.

Various inventory models with high demand rate and low prices are proposed. An inventory model with the demand rate as a linear function of selling price and a declining deterioration rate as a function with respect to time of storing items was constructed by Mondal et al. (2003). Likewise, an inventory model for deteriorating items with the rate of demand fluctuates with the selling price and deterioration rate fluctuates with the time of storing items, was proposed by Mukhopadhyay et al. (2005). An EOQ inventory model with price-dependent demand for estimating retailer's price and lot size, incase supplier permits delayed payments, was investigated by Teng et al. (2005). The algorithms for estimating optimum solution for an EOQ model with quantity discounts and price based demand were investigated by Transchel and Minner (2008). Ding (2010) proposed a pricedependent demand model in the single period inventory system with price adjustment, assuming stochastic demand rate with a normal distribution is sensitive to the selling price.

Several inventory models were constructed on the supposition of the rate of demand jointly based on stock level and selling price. An inventory model was investigated by Hou and Lin (2006) for deteriorating items with an assumption of demand rate depends jointly on stock level and selling price both. An EOQ model for single vendor and multi retailers for a product where demand rate is a linear function including the stock level and the price value together were analyzed by Panda et al. (2010).

Various inventory studies include the unit holding cost as a variable. An inventory model with nonlinear holding cost dependent on storing-time period was proposed by Ferguson et al. (2007) with an assumption that the selling price declines non-linearly with respect to storing time, the modeling includes surcharges of delivering occasional discounts in sale price and orders for consumable items.

Many inventory models consist of variable holding cost as well as variable demand rate by assuming demand rate depending on stock. Assuming the holding cost increases with respect to storage time, an EOQ model with demand rate based on the stock was proposed by Alfares (2007). This model was extended by Alfares (2014) to an EPQ model, having a limited rate of production, 
International Journal of Mathematical, Engineering and Management Sciences

Vol. 3, No. 3, 245-257, 2018

https://dx.doi.org/10.33889/IJMEMS.2018.3.3-017

initial inventory level as non-zero with profit maximizing as objective. By modifying Alfares (2007) model, Zhao and Zhong (2008) assumed the holding cost to be a decreasing function of the storing time. An EOQ model consisting of demand rate and holding cost based on stock level was investigated by Pando et al. (2012) The holding cost is supposed to be a non-linear function, jointly of the length storing-time and the inventory level by maximizing the final profit for a model with demand rate based on inventory level by Pando et al. (2013). Khanna et al. (2017) proposed an inventory modelling for deteriorating items with imperfect quality demand depending on selling price and shortage are fully backordered under credit financing.

An inventory model with demand rate based on the sale price and the quality of items was estimated by Datta (2013). Kumar et al (2012) proposed another model with deteriorating items where holding cost is a function of trade credit with time variable. An EOQ model dealing with demand rate based together on the level of inventory and selling price, was investigated by Datta and Paul (2001), in which holding cost changes with respect to the storing time. San-José and García-Laguna (2009) proposed an EOQ model with backorders and all-units discounts.

Several inventory models were proposed consisting of purchasing cost depending on the order size are subject to all units or discounts offered on increased quantity, a reduction in single price is applicable to every unit in the specified order in all-units discounts. To estimate the optimal discount policy, Weng (1995) constructed an inventory model without shortages; by assuming the demand rate based on sale price and constant holding cost, to maximize the profits by including incremental quantity discounts as well as all-units discounts. Many other researchers like Burwell et al. (1997), Chang (2013) and Wee (1999) and much more investigated the optimal policies by quantity discounts with different constraints. Goh and Sharafali (2002) considered an inventory model with a supplier offering discounts to a reseller at random epochs.

Yang (2004), investigated optimal policies for obtaining selling price and a number of orders for the deteriorating items, where the linear rate of demand is dependent on selling price and the discounts on quantity are offered by the supplier. The model objective is to reduce the overall inventory cost to the minimum, with assumptions of no shortages with constant holding cost. Optimization of inventory model is done for a non-instantaneous deteriorating item by Ouyang et al. (2008), where the rate of demand is based on a stock level with all-units quantity discounts offered by the supplier. Permissible shortage with backordering rate is represented by a random variable and holding cost as a function of the purchasing cost.

An inventory model with the rate of demand is based on present stock with promotional temporary discounts, where the model analyzes the outcomes of discounts on quantity offered by the supplier on the retailer's policies of ordering was formulated by Shah (2012). Alfares (2015) proposed a recent inventory model with inventory level dependent demand and the holding cost are subject to storing-time as well as the unit purchasing cost. Alfares and Ghaithan (2016) introduced a model on inventory with the rate of demand is based on the price of selling items, cost of holding items depends on the time of storing products, and purchasing cost based on the size of order which evaluates quantity and selling price of items.

In all six sections are there in this article. Section 2 consists of notations and assumptions. Mathematical model and solution methodology are derived in section 3. In section 4, the validation of the model is justified with a numerical example with sensitivity analysis. And lastly, conclusions of the study are extracted in section 5 . 
International Journal of Mathematical, Engineering and Management Sciences

Vol. 3, No. 3, 245-257, 2018

https://dx.doi.org/10.33889/IJMEMS.2018.3.3-017

\section{Notations and Assumptions}

\subsection{Notations}

$\begin{array}{ll}I(t) & \text { Inventory level at time } t \\ A & \text { Ordering cost per order (in dollars) } \\ Q & \text { Order size } \\ q_{j} & \text { Maximum order size for the range of purchasing cost, } j, \quad j=1,2, \ldots J \\ P C(Q) & \text { Purchasing cost -a function of order size } Q \text { per unit (in dollars) } \\ C_{j} & \text { Purchasing cost per unit for order size } Q \text { is in the range } j, \quad j=1,2, \ldots J \\ H C(t) & \text { Unit holding cost per unit time } t \text { (in dollars) } \\ h & \text { Constant holding cost co-efficient } \\ i & \text { Time varying holding cost co-efficient } \\ T & \text { Replenishment cycle time } \\ p & \text { Selling price (in dollars) } \\ \theta & \text { Rate of deterioration per item } \\ R t(p, I(t)) & \text { Rate of market demand-a function of sale price and level of inventory at } t \text { time } \\ a & \text { Constant demand rate co-efficient; } a>0 \\ b & \text { Elasticity of inventory level at time } t, b>0 \\ c & \text { Selling price dependent demand rate co-efficient, } c>0 \\ T P_{\max } & \text { Maximum total profit in the iterative procedure (in dollars) } \\ T C_{j}(T, p) & \text { The total cost per unit time of the inventory system (in dollars) } \\ T P_{j}(T, p) & \text { The total profit per time unit of the inventory system (in dollars) }\end{array}$

\subsection{Assumptions}

(a) The holding cost of products are classified into two parts: The first part deals with the constant cost co-efficient $h$, and the second part includes variable cost co-efficient $i$ which grows linearly with the respect to the storage time length. So, the total holding cost at unit time $t$ is computed as,

$$
H(t)=h(1+i t)
$$

(b) The total purchasing cost depends on all-units quantity discounts. Let $C_{j}$ be the unit purchasing cost, which is a decreasing step function. Therefore, the total purchasing cost per unit time is a function of order size $Q$, given by,

$$
P C(Q)=\frac{C_{j} Q}{T}, \quad \text { if } q_{j-1}<Q \leq q_{j}, \quad C_{1}>C_{2} \ldots>C_{j}
$$

(c) The rate of demand $R t$ is represented by a linearly decreasing function of selling price per unit, $p$ and level of inventory at the time $t$, as $I(t)$. Therefore

$$
R t(p, I(t))=a+b I(t)-c p
$$

(d) Shortages are impermissible.

(e) The system consists of a single item. 
International Journal of Mathematical, Engineering and Management Sciences

Vol. 3, No. 3, 245-257, 2018

https://dx.doi.org/10.33889/IJMEMS.2018.3.3-017

(f) The unit purchase cost is always less than the selling price of item, Therefore, $C_{j}<p$

(g) The item undergoes deterioration while kept in storage during a replenishment cycle [0, T]. Let the deterioration rate be $\theta$ per item.

\section{Formulation of Mathematical Model and Solution Methodology 3.1 Mathematical Model Formulation}

In this section, an inventory model is to be constructed with consideration of all the above stated assumptions. The level of inventory at any time $t$ is represented in the form of deterioration rate $\theta$ and market demand rate $\operatorname{Rt}(P, I(t))$, by the following equation,

$$
\frac{d I(t)}{d t}=-\theta I(t)-R t(p, I(t)) \quad \text { where, } \quad I(0)=Q \text { and } I(T)=0
$$

On solving equation (5), and substituting the boundary condition $I(T)=0$, represented at the completion of cycle, we obtain,

$$
I(t)=\frac{(a-c p)}{(\theta+b)}\left(e^{(\theta+b) T}-1\right)
$$

Then, switching the boundary condition $I(0)=Q$, represented at the starting of each cycle into equation (6) generates,

$$
Q=\frac{(a-c p)}{(\theta+b)}\left(e^{(\theta+b) T}-1\right)
$$

The objective of the proposed model is to maximize the total profit $T P_{j}(T, P)$ per unit time of inventory system. The profit function includes the following components:

(i) The Ordering cost: Let $A$ be the ordering cost per order. Therefore, ordering cost per unit time $T$ is given by,

$$
O C=\frac{A}{T} \text {. }
$$

(ii) The Purchasing cost: Let $C_{j}$ represents the purchasing cost per order. Therefore, purchasing cost per unit time $T$ for quantity $Q$ is given by,

$$
P C=\frac{C_{j} Q}{T} \text {. }
$$

(iii) The Holding cost: The total holding cost per unit time $T$ during one cycle is calculated using inventory level $I(t)$ as,

$$
H C=\frac{\int_{0}^{T} H(t) I(t) d t}{T} .
$$


International Journal of Mathematical, Engineering and Management Sciences

Vol. 3, No. 3, 245-257, 2018

https://dx.doi.org/10.33889/IJMEMS.2018.3.3-017

(iv) The Sales revenue: The sales revenue is calculated as the selling price per unit $p$ times the total number of sold units in $[0, T]$ per cycle time given by,

$$
S R=\frac{p \int_{0}^{T} R t(T, p) d t}{T} .
$$

\subsection{Solution Procedure}

Therefore, for each cycle the total cost, $T C_{j}(T, p)$ is computed as,

$T C_{j}(T, p)=O C+P C+H C$.

$T C_{j}(T, p)=\frac{A}{T}+\frac{C_{j} Q}{T}+\frac{\int_{0}^{T} H(t) I(t) d t}{T}$

So, the total profit per unit time is calculated by,

Total profit $T P_{j}(T, p)=S R-T C_{j}(T, p)$.

Therefore, $T P_{j}(T, p)=\frac{p \int_{0}^{T} R t(T, p) d t}{T}-T C_{j}(T, p)$

Now, to maximize the total profit, we apply the following necessary and sufficient condition:

$$
\frac{\partial T P_{j}(T, p)}{\partial T}=0, \frac{\partial T P_{j}(T, p)}{\partial p}=0
$$

Now to check the concavity of profit function of obtained solution, we have adopted the below stated algorithm,

Step-1: Assigning the inventory parameters some hypothetical values.

Step-2: Obtaining the solutions by solving simultaneous equations in equation (10) utilizing the mathematical software Maple XVIII.

Step-3: Checking the below stated second order sufficient conditions at obtained values from equation (10)

$$
\frac{\partial^{2} T P_{j}(T, p)}{\partial T^{2}}<0, \frac{\partial^{2} T P_{j}(T, p)}{\partial p^{2}}<0
$$

Finally, on satisfying equation (11) for the obtained values, the concave profit function is obtained and then stop. 
International Journal of Mathematical, Engineering and Management Sciences

Vol. 3, No. 3, 245-257, 2018

https://dx.doi.org/10.33889/IJMEMS.2018.3.3-017

To calculate the optimum decision variables and total profit with quantity discounts, we adopt below stated algorithm.

Step-1: Set $j=J$ and $T P_{\max }=0$; where $T P_{\max }$ is maximum total profit.

Step-2: Substituting $C_{j}$ and all the provided values $A, a, b, c, h, i, \theta$ in equations (10) and solving for selling price $(p)$ and replenishment cycle length $(T)$ and from equation (7), evaluating ordering quantity.

- If $Q$ satisfies the condition, $\left(q_{j-1}<Q \leq q_{j}\right)$, then a feasible solution is obtained. Inserting the optimum solutions of $p$ and $T$ into equation (9) to calculate $T P_{j}(T, p)$. If $T P_{j}(T, p)>T P_{\max }, \operatorname{set} T P_{\max }=T P_{j}(T, p)$. Then go to step-5.

- If $Q$ does not satisfies the condition, then obtained a solution is infeasible and go to step3.

Step-3: Substituting the values of purchasing $\operatorname{cost} C_{j}$, Quantity $Q=q_{j-1}, A, a, b, c, h, i, \theta$ in the equation (9) and equation (10) and finding the solution for $p, T$ to calculate $T P_{j}(T, p)$. If $T P_{j}(T, p)>T P_{\max }$ then set $T P_{\max }=T P_{j}(T, p)$ and go to step-4.

Step-4: If $j \geq 2$ and setting $j=j-1$ and proceeding to step-1. If $j=1$, then proceeding to step-5.

Step-5: The obtained final solution $T P_{\max }$ represents the feasible solution. Computing the optimal solution by utilizing the optimal values of $p, T, Q, T P_{j}(T, p)$, and stop.

The quantity value $Q$ should be approximated to the adjacent integer for finding the optimum solution procedure. The objective of this article is to be fulfilled to maximize per unit time total profit subject to the decision variables selling price, and cycle time. For checking the validity of the model, a below stated numerical example for the inventory parameters is considered.

\section{Numerical Example with Sensitivity Analysis}

Example: With the given values in their appropriate standard units $a=160, b=0.01, c=1.6, h=0.99, i=0.9, \theta=0.09, A=600, C_{1}=5, C_{2}=4.75, C_{3}=4.5, q_{1}=0, q_{2}=100, q_{3}=200$.

By using above algorithms, we will check the concavity of profit function and find the optimum solution also doing the sensitivity analysis of decision variables by varying the inventory parameters $-20 \%$ to $20 \%$.

Following steps demonstrates the solution procedure:

Step-1: Setting $j=3$ and $T P_{\max }=0$.

First Iteration: Starting with $j=3$. 
International Journal of Mathematical, Engineering and Management Sciences

Vol. 3, No. 3, 245-257, 2018

https://dx.doi.org/10.33889/IJMEMS.2018.3.3-017

Step-2: Considering $C_{3}=\$ 4.5$ (with $\left.Q \geq 200\right)$.

Initializing with the lowermost purchasing cost of the unit item, $C_{3}=\$ 4.5$, inserting the given values into equation (10) we get, $p=\$ 53.64, T=2.46$ months then by equation (7) and equation (9) we get, $Q=206, T P_{3}(T, p)=\$ 3240.49$. Since, $Q=206>200$ this solution is feasible. Therefore, we set $T P_{\max }=3240.49$. Then proceeding to step-3.

Step-3: Setting $j=2$ and go to step-2.

Second Iteration: Stating $j=2$.

Step-2: Considering $C_{2}=\$ 4.75$, (with $\left.100 \leq Q<200\right)$.

Replacing purchasing cost per unit $C_{2}=\$ 4.75$ and the various other specified values into equation (10) and on solving we get, selling-price $p=\$ 53.77, T=2.45$ months then by equation (7) and equation (9), we get, $T P_{3}(T, p)=\$ 3219.50, Q=205>200$, So, therefore, the obtained solution is infeasible and then proceeding to step-3.

Step-3: $C_{2}=\$ 4.75, \quad Q=100$.

Assuming the lowest unit purchase cost, $C_{2}=\$ 4.75$ and computing the lowest order size for the provided cost, $\mathrm{Q}=100$ substituting the specified values into equation (10) and after finding the solution we get:

$p=\$ 53.77, T=2.45, Q=100$, then by equation (9) we $\operatorname{get} T P_{3}(T, p)=\$ 3219.50$. We have $3240.49>3219.50$. Therefore, $T P_{\max }=\$ 3240.49$. As such we obtain a feasible solution therefore, the iterative procedure is stopped and then proceeding to step-5.

Step-5: Concluding Solution.

The result obtained in step- 2 of the first iteration is recognized as the optimum solution with $C_{3}=\$ 4.5$ as unit purchasing cost, by the below stated optimum values:

$p=\$ 53.64, T=2.46$ months, $Q=206, T P_{3}(T, p)=\$ 3240.49$.

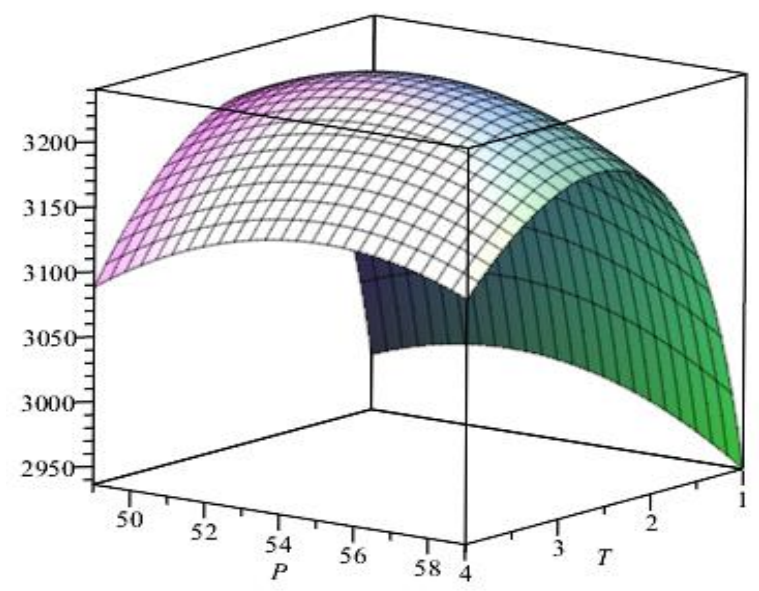

Fig. 1. Concavity of profit function 
International Journal of Mathematical, Engineering and Management Sciences

Vol. 3, No. 3, 245-257, 2018

https://dx.doi.org/10.33889/IJMEMS.2018.3.3-017

Fig. 1 demonstrates the concave nature of the profit function at an optimal solution and sensitivity analysis of decision variables on varying various inventory parameters is shown in Table 1 . The managerial insights on the basis of variation of inventory parameters are also proposed.

Table 1. Impact on various decision variables on varying various inventory parameters

\begin{tabular}{|c|c|c|c|c|c|c|}
\hline \multirow{6}{*}{$\begin{array}{l}\text { Inventory Parameters } \\
\text { Constant demand rate co-efficient } \\
\text { (a) }\end{array}$} & \multicolumn{6}{|c|}{$\begin{array}{l}\begin{array}{l}\text { Impact on various decision variables on varying various inventory parameters } \mathbf{- 2 0 \%} \\
\text { to } 20 \%\end{array}\end{array}$} \\
\hline & \multicolumn{2}{|c|}{$-20 \%$} & \multirow{2}{*}{$\begin{array}{l}-10 \% \\
2.5473 \\
\end{array}$} & \multirow{2}{*}{$\begin{array}{c}0 \\
2.4605\end{array}$} & \multirow{2}{*}{$\begin{array}{c}10 \% \\
2.3883\end{array}$} & \multirow{2}{*}{$\begin{array}{c}20 \% \\
2.3274\end{array}$} \\
\hline & $T$ & 2.6533 & & & & \\
\hline & $p$ & 43.7997 & 48.7127 & 53.6430 & 58.5861 & 63.5390 \\
\hline & $Q$ & 176 & 192 & 206 & 221 & 236 \\
\hline & $T P_{j}$ & 1901.052 & 2529.7757 & 3240.499 & 4032.969 & 4906.996 \\
\hline \multirow{4}{*}{$\begin{array}{l}\text { Elasticity of inventory level at time } t \\
\text { (b) }\end{array}$} & $T$ & 2.4237 & 2.4419 & 2.4605 & 2.4796 & 2.4990 \\
\hline & $p$ & 53.6154 & 53.6290 & 53.6430 & 53.6574 & 53.6721 \\
\hline & $Q$ & 203 & 204 & 206 & 208 & 210 \\
\hline & $T P_{j}$ & 3231.082 & 3235.768 & 3240.499 & 3245.276 & 3250.101 \\
\hline \multirow{4}{*}{$\begin{array}{l}\text { Selling price dependent demand rate } \\
\text { co-efficient }(c)\end{array}$} & $T$ & 2.4981 & 2.4761 & 2.4605 & 2.4495 & 2.4417 \\
\hline & $p$ & 66.1730 & 59.2110 & 53.6430 & 49.0888 & 45.2948 \\
\hline & $Q$ & 213 & 209 & 206 & 204 & 201 \\
\hline & $T P_{j}$ & 4249.647 & 3688.7579 & 3240.499 & 2874.156 & 2569.237 \\
\hline \multirow{4}{*}{$\begin{array}{l}\text { Constant holding cost co-efficient } \\
\text { (h) }\end{array}$} & $T$ & 2.6762 & 2.5602 & 2.4605 & 2.3736 & 2.2967 \\
\hline & $p$ & 53.5636 & 53.6037 & 53.6430 & 53.6814 & 53.7189 \\
\hline & $Q$ & 227 & 216 & 206 & 198 & 191 \\
\hline & $T P_{j}$ & 3276.525 & 3257.934 & 3240.499 & 3224.036 & 3208.406 \\
\hline \multirow{4}{*}{$\begin{array}{l}\text { Time varying holding cost co- } \\
\text { efficient }(i)\end{array}$} & $T$ & 2.5806 & 2.5175 & 2.4605 & 2.4088 & 2.3616 \\
\hline & $p$ & 53.6356 & 53.6390 & 53.6430 & 53.6474 & 53.6522 \\
\hline & $Q$ & 218 & 212 & 206 & 202 & 197 \\
\hline & $T P_{j}$ & 3255.402 & 3247.767 & 3240.499 & 3233.554 & 3226.898 \\
\hline \multirow{4}{*}{ Deterioration rate $(\theta)$} & $T$ & 2.1591 & 2.2018 & 2.4605 & 3.0226 & 4.0426 \\
\hline & $p$ & 67.7408 & 59.6041 & 53.6430 & 49.1175 & 45.4863 \\
\hline & $Q$ & 124 & 159 & 206 & 287 & 434 \\
\hline & $T P_{j}$ & 632.9655 & 1823.572 & 3240.499 & 4861.995 & 6699.445 \\
\hline \multirow{4}{*}{ The ordering cost per order $(A)$} & $T$ & 2.2628 & 2.3653 & 2.4605 & 2.5497 & 2.6335 \\
\hline & $p$ & 53.4897 & 53.5683 & 53.6430 & 53.7145 & 53.7833 \\
\hline & $Q$ & 188 & 198 & 206 & 215 & 222 \\
\hline & $T P_{j}$ & 3291.286 & 3265.362 & 3240.499 & 3216.55 & 3193.4 \\
\hline
\end{tabular}


International Journal of Mathematical, Engineering and Management Sciences

Vol. 3, No. 3, 245-257, 2018

https://dx.doi.org/10.33889/IJMEMS.2018.3.3-017

Following are the managerial insights based on the sensitivity analysis for the decision variables based on the observations in Table 1.

(i) Constant demand rate co-efficient ( $a$ )

When the rate of constant demand grows, there is an increment in total profit by decreasing the selling price along with greater lot size and shortening the replenishment cycle length. So, it is advisable to the firm to opt an option of lowering the selling price of the deteriorating products in order to maintain the constant demand rate in market by ordering a larger lot sizes and vacating the inventory level quickly by offering quantity discounts to customers resulting in uplifting of the total profit of the firm, showing shorter cycle length.

\section{(ii) Elasticity of Inventory level at timet, $(b)$}

With the rise in inventory level co-efficient, each decision variable is increased. As such displaying more and more products, naturally more customers are attracted resulting in high profit level. So, it is desirable to prefer a high selling price for a longer period with quantity discounts on deteriorating items, therefore raising the total profit of the firm.

\section{(iii) Selling price dependent rate co-efficient $(c)$}

Fall in values of each decision variable is seen, with the variation in $c$. As such with the higher value of $c$, the rate of demand decreases resulting in collapsing of the total profit of the firm. So, it is advisable to have a lower selling price of the product and vacating the deteriorating stock quickly but with no discounts resulting in lowering the order size.

\section{(iv) Constant holding cost co-efficient $(h)$}

Selling price and total cost enhance with the increase in holding cost co-efficient, rest other decision variables decreases. As such, if products with higher sale price are stored for a longer period, market demand decreases resulting in elapse of the total profit. So, it should be a practical view for the firm for selling the deteriorating products rapidly by lowering the cycle length, in order to boost the total profit.

\section{(v) Time varying holding cost co-efficient $(i)$}

As such with respect to time, if the holding cost co-efficient increases, an increment in sale price and the total cost is seen. Therefore, it is suitable for the firm to sale the products in the shorter time period to raise the total profit otherwise, the product starts deteriorating.

\section{(vi) Deterioration rate $(\theta)$}

As such, when the rate of deterioration increases, the firm is suggested to lower the selling price, to clear the stock and to boost the total profit.

\section{(vii) The ordering cost $(A)$}

With the increase in ordering cost per order, obviously, the selling price of deteriorating product increases with a rise in total cost and declining total profit of firm for higher order sizes with longer cycle length. So, it is recommended to offer discounts on products in order to gain total profit for the firm. 
International Journal of Mathematical, Engineering and Management Sciences

Vol. 3, No. 3, 245-257, 2018

https://dx.doi.org/10.33889/IJMEMS.2018.3.3-017

\section{Conclusions}

This article proposes an inventory system with variable holding cost, variable purchasing cost and variable demand rate, rather than supposing the constant values for these parameters. In order to visualize the practical scenario, the demand rate is dependent on selling price and time, a cost associated with holding of items based on storage period, and the purchasing cost on the basis of the size of the order, depending on all units quantity discounts are considered for deteriorating items. An algorithm is then designed to generate the optimal solution, which maximizes the total profit. Further, by demonstrating a numerical example, the effectiveness of proposed algorithm is shown, and sensitivity-analysis about inventory parameters is conducted for decision-making visions.

The sensitivity-analysis results, displays variation in values of decision variables and the total profit function, where companies should boost up the market demand by well-planned marketing policies by increasing revenues. By reducing purchasing cost and ordering cost, the demand will increase. The effective steps are needed to reduce the deterioration of items, to facilitate the increment in total profit.

Furthermore, one can include shortages in the system or may consider a variable demand by forming a non-linear function. The preservation technology can be inserted to reduce the deterioration rate. Also, utilizing the concept of efforts in advertising or human resources can be inserted to boost the demand rate.

\section{Acknowledgement}

The authors will like to thank reviewers for their constructive comments. The authors thank DST-FIST MSI097 for technical support to carry out this research.

\section{References}

Alfares, H. K. (2007). Inventory model with stock-level dependent demand rate and variable holding cost. International Journal of Production Economics, 108(1), 259-265.

Alfares, H. K. (2014). Production-inventory system with finite production rate, stock-dependent demand, and variable holding cost. RAIRO-Operations Research, 48(1), 135-150.

Alfares, H. K. (2015). Maximum-profit inventory model with stock-dependent demand, time-dependent holding cost, and all-units quantity discounts. Mathematical Modelling and Analysis, 20(6), 715-736.

Alfares, H. K., \& Ghaithan, A. M. (2016). Inventory and pricing model with price-dependent demand, timevarying holding cost, and quantity discounts. Computers of Industrial Engineering, 94,170-177.

Anand, A., \& Bansal, G. (2016). Predicting customer's satisfaction (dissatisfaction) using logistic regression. International Journal of Mathematical, Engineering and Management Sciences, 1(2), 77-88.

Burwell, T. H., Dave, D. S., Fitzpatrick, K. E., \& Roy, M. R. (1997). Economic lot size model for pricedependent demand under quantity and freight discounts. International Journal of Production Economics, 48(2), 141-155.

Chang, H. C. (2013). A note on an economic lot size model for price-dependent demand under quantity and freight discounts. International Journal of Production Economics, 144(1), 175-179. 
International Journal of Mathematical, Engineering and Management Sciences

Vol. 3, No. 3, 245-257, 2018

https://dx.doi.org/10.33889/IJMEMS.2018.3.3-017

Datta, T. K. (2013). An inventory model with price and quality dependent demand where some items produced are defective. Advances in Operations Research.

Datta, T. K., \& Paul, K. (2001). An inventory system with stock-dependent, price-sensitive demand rate. Production Planning and Control, 12(1), 13-20.

Ding, Z. (2010, November). An inventory coordination scheme of single-period products under pricedependent demand. In E-Product E-Service and E-Entertainment (ICEEE), 2010 International Conference on (pp. 1-4). IEEE.

Ferguson, M., Jayaraman, V., \& Souza, G. C. (2007). Note: An application of the EOQ model with nonlinear holding cost to inventory management of perishables. European Journal of Operational Research, $180(1), 485-490$.

Goh, M., \& Sharafali, M. (2002). Price-dependent inventory models with discount offers at random times. Production and Operations Management, 11(2), 139-156.

Hou, K. L. \& Lin, L. C. (2006). An EOQ model for deteriorating items with price-and stock-dependent selling rates under inflation and time value of money. International Journal of Systems Science, 37(15), 11311139.

Khanna A., Gautam P., \& Jaggi C. K. (2017). Inventory modeling for deteriorating imperfect quality items with selling price dependent demand and shortage backordering under credit financing. International Journal of Mathematical, Engineering and Management Sciences, 2(2), 110-124.

Kumar, M., Chauhan A., \& Kumar R. (2012). A deterministic inventory model for deteriorating items with price dependent demand and time varying holding cost under trade credit. International Journal of Soft Computing and Engineering, 2(1), 2231-2307.

Lee, Y. P. \& Dye, C. Y. (2012). An inventory model for deteriorating items under stock-dependent demand and controllable deterioration rate. Computers and Industrial Engineering, 63(2), 474-482.

Min, J. \& Zhou, Y. W. (2009). A perishable inventory model under stock-dependent selling rate and shortagedependent partial backlogging with capacity constraint. International Journal of Systems Science, 40(1), 33-44.

Mondal, B., Bhunia, A. K., \& Maiti, M. (2003). An inventory system of ameliorating items for price dependent demand rate. Computers and Industrial Engineering, 45(3), 443-456.

Mukhopadhyay, S., Mukherjee, R. N., \& Chaudhari, K. S. (2005). An EOQ model with two-parameter Weibull distribution deterioration and price-dependent demand. International Journal of Mathematical Education in Science and Technology, 36(1), 25-33.

Ouyang, L. Y., Wu, K. S. \& Yang, C. T. (2008). Retailer's ordering policy for non-instantaneous deteriorating items with quantity discount, stock-dependent demand and stochastic backorder rate. Journal of the Chinese Institute of Industrial Engineers, 25(1), 62-72.

Panda, D., Maiti, M. K., \& Maiti, M. (2010). Two warehouse inventory models for single vendor multiple retailers with price and stock dependent demand. Applied Mathematical Modelling, 34(11), 3571-3585.

Pando, V., José, L. A., Laguna, J. G., \& Sicilia, J. (2013). An economic lot-size model with non-linear holding cost hinging on time and quantity. International Journal of Production Economics, 145(1), 294-303.

Pando, V., Laguna, J. G., José, L. A., \& Sicilia, J. (2012). Maximizing profits in an inventory model with both demand rate and holding cost per unit time dependent on the stock level. Computers and Industrial Engineering, 62(2), 599-608.

Sana, S., \& Chaudhari K. S. (2004). A stock-review EOQ model with stock-dependent demand, quadratic deterioration rate. Advanced Modeling and Optimization, 6(2), 25-32. 
International Journal of Mathematical, Engineering and Management Sciences

Vol. 3, No. 3, 245-257, 2018

https://dx.doi.org/10.33889/IJMEMS.2018.3.3-017

San-José, L. A., \& García-Laguna, J. (2009). Optimal policy for an inventory system with backlogging and all-units discounts: Application to the composite lot size model. European Journal of Operational Research, 192(3), 808-823.

Shah, N. H. (2012). Ordering policy for inventory management when demand is stock-dependent and a temporary price discount is linked to order quantity. Revista Investigación Operacional, 33(3), 233-244.

Teng, J. T., Chang, C. T., \& Goyal, S. K. (2005). Optimal pricing and ordering policy under permissible delay in payments. International Journal of Production Economics, 97(2), 121-129.

Transchel, S., \& Minner, S. (2008). Coordinated lot-sizing and dynamic pricing under a supplier all-units quantity discount. BuR-Business Research, 1(1), 125-141.

Wee, H. M. (1999). Deteriorating inventory model with quantity discount, pricing and partial backordering. International Journal of Production Economics, 59(1), 511-518.

Weng, Z. K. (1995). Modeling quantity discounts under general price-sensitive demand functions: Optimal policies and relationships. European Journal of Operational Research, 86(2), 300-314.

Yang P. C. (2004). Pricing strategy for deteriorating items using quantity discount when demand is price sensitive. European Journal of Operational Research, 157(2), 389-397.

Yang, H. L., Teng, J. T., \& Chern, M. S. (2010). An inventory model under inflation for deteriorating items with stock-dependent consumption rate and partial backlogging shortages. International Journal of Production Economics, 123(1), 8-19.

Zhao, M., \& Zhong, B., (2008). Inventory model with stock-level dependent demand rate and variable holding cost. Journal of Chongqing Institute of Technology (Natural Science), 10, 23. 